\title{
Prevalence and Medication Treatment of Opioid Use Disorder Among Primary Care Patients with Hepatitis C and HIV
}

\author{
Judith I. Tsui, MD MPH' , Mary A. Akosile, MS, MPH' , Gwen T. Lapham, PhD, MPH, MSW', \\ Denise M. Boudreau, PhD' , Eric A. Johnson, MS², Jennifer F. Bobb, PhD', \\ Ingrid A. Binswanger, MD, MPH, MS ${ }^{3}$, Bobbi Jo H. Yarborough, Psy $D^{4}$, \\ Joseph E. Glass, PhD, MSW', Rebecca C. Rossom, MD, MS ${ }^{5}$, Mark T. Murphy, MD', \\ Chinazo O. Cunningham, MD, MS ${ }^{7}$, Julia H. Arnsten, MD, MPH ${ }^{7}$, Manu Thakral, PhD, NP', \\ Andrew J. Saxon, $M D^{9}$, Joseph O. Merrill, MD, MPH ${ }^{7}$, Jeffrey H. Samet, MD, MA, MPH' \\ Gavin B. Bart, MD, PhD ${ }^{17}$, Cynthia I. Campbell, PhD, MPH'12, Amy M. Loree, PhD 13, \\ Angela Silva, DBA, MAOL, CRA ${ }^{6}$, Angela L. Stotts, $P h D^{14}$, Brian Ahmedani, $P h D^{13}$, \\ Jordan M Braciszewski, $P h D^{13,15}$, Rulin C. Hechter, PhD, MS, MD ${ }^{16}$, \\ Thomas F. Northrup, PhD ${ }^{14}$, Viviana E. Horigian, MD, MHA ${ }^{17}$, and Katharine A. Bradley, \\ $M D, M P H^{2} \odot$
}

\begin{abstract}
'University of Washington/Harborview Medical Center, Seattle, USA; ${ }^{2}$ Kaiser Permanente Washington Health Research Institute, 1730 Minor Avenue, STE 1600, Seattle, WA, USA; ${ }^{3}$ Kaiser Permanente Colorado, Colorado Permanente Medical Group, and the University of Colorado School of Medicine, Aurora, USA; ${ }^{4}$ Kaiser Permanente Northwest Center for Health Research, Portland, USA; ${ }^{5}$ HealthPartners Institute, University of Minnesota, Bloomington, USA; ${ }^{M}$ MultiCare Institute for Research and Innovation, MultiCare Health System WA, Seattle, USA; ${ }^{7}$ Albert Einstein College of Medicine, Montefiore Medical Center, New York City, USA; ${ }^{8}$ College of Nursing and Health Sciences, University of Massachusetts Boston, Boston, USA; ${ }^{9}$ Center of Excellence in Substance Addiction Treatment and Education, VA Puget Sound Health Care System/University of Washington School of Medicine, Seattle, USA; ${ }^{10}$ Boston University/Boston Medical Center, Boston, USA; ${ }^{11}$ Hennepin Healthcare, University of Minnesota, Minneapolis, USA; ${ }^{12}$ Division of Research, Kaiser Permanente Northern California, Oakland, USA; ${ }^{13}$ Center for Health Policy and Health Services Research, Henry Ford Health System, Detroit, USA; ${ }^{14}$ Department of Family and Community Medicine, McGovern Medical School, University of Texas Health Science Center at Houston (UTHealth), Houston, USA; ${ }^{15}$ Department of Psychiatry, Henry Ford Health System, Detroit, USA;

${ }^{16}$ Department of Research and Evaluation, Kaiser Permanente Southern California, Oakland, USA; ${ }^{17}$ Department of Public Health Sciences, Miller School of Medicine, University of Miami, Florida, USA.
\end{abstract}

BACKGROUND: Hepatitis C and HIV are associated with opioid use disorders (OUD) and injection drug use. Medications for OUD can prevent the spread of HCV and HIV. OBJECTIVE: To describe the prevalence of documented OUD, as well as receipt of office-based medication treatment, among primary care patients with HCV or HIV.

DESIGN: Retrospective observational cohort study using electronic health record and insurance data.

PARTICIPANTS: Adults $\geq 18$ years with $\geq 2$ visits to primary care during the study (2014-2016) at 6 healthcare systems across five states (CO, CA, OR, WA, and MN).

MAIN MEASURES: The primary outcome was the diagnosis of OUD; the secondary outcome was OUD treatment with buprenorphine or oral/injectable naltrexone. Prevalence of OUD and OUD treatment was calculated across four groups: HCV only; HIV only; HCV and HIV; and neither HCV nor HIV. In addition, adjusted odds ratios (AOR)

Prior Presentations Tsui JI, Lapham G, Boudreau DM, Johnson E, Binswanger IA, Cunningham CO, Thakral M, Arnsten JH, Saxon AJ, Merrill JO, Samet JH, Bart G, Campbell CI, Bradley KA. Opioid use disorder among persons with Hepatitis C and HIV: Data from 8 health systems. Oral presentation at the College on Problems of Drug Addiction Annual Meeting. June 12,2018. San Dieao. CA.USA

Received April 8, 2020

Accepted December 3, 2020

Published online February 10, 2021 of OUD treatment associated with $\mathrm{HCV}$ and HIV (separately) were estimated, adjusting for age, gender, race/ethnicity, and site.

KEY RESULTS: The sample included 1,368,604 persons, of whom 10,042 had HCV, $5821 \mathrm{HIV}$, and 422 both. The prevalence of diagnosed OUD varied across groups: $11.9 \%$ (95\% CI: $11.3 \%, 12.5 \%$ ) for those with $\mathrm{HCV} ; 1.6 \%$ (1.3\%, 2.0\%) for those with HIV; 8.8\% (6.2\%, 11.9\%) for those with both; and $0.92 \%(0.91 \%, 0.94 \%)$ among those with neither. Among those with diagnosed OUD, the prevalence of OUD medication treatment was $20.9 \%, 16.0 \%$, $10.8 \%$, and $22.3 \%$, for those with HCV, HIV, both, and neither, respectively. HCV was not associated with OUD treatment $(\mathrm{AOR}=1.03 ; 0.88,1.21)$, whereas patients with HIV had a lower probability of OUD treatment $(\mathrm{AOR}=$ $0.43 ; 0.26,0.72$ ).

CONCLUSIONS: Among patients receiving primary care, those diagnosed with HCV and HIV were more likely to have documented OUD than those without. Patients with HIV were less likely to have documented medication treatment for OUD.

KEY WORDS: opioid use disorders; hepatitis C; HIV; buprenorphine; naltrexone. 
J Gen Intern Med 36(4):930-7

DOI: $10.1007 / \mathrm{s} 11606-020-06389-7$

(c) Society of General Internal Medicine 2021

\section{INTRODUCTION}

The USA is experiencing a crisis of opioid use disorders (OUDs). In 2017, there were 47,600 people who died from opioid-related overdoses ${ }^{1}$ and an estimated 2.1 million Americans had an OUD, of whom 652,000 had a heroin-involved OUD. ${ }^{2}$ Patients with OUD who use pharmaceutical opioids may transition to injection drug use, ${ }^{3}$ and up to three-quarters of persons with OUD entering treatment report injecting drugs. ${ }^{4}$

Both hepatitis $\mathrm{C}$ virus (HCV) and HIV infection are spread through injection drug use, and these diseases are on the rise in communities affected by the opioid crisis. ${ }^{5,}{ }^{6}$ Hepatitis $\mathrm{C}$ is currently the leading cause of infectious disease related death in the USA, ${ }^{7}$ surpassing deaths from HIV combined with other infectious causes. Although HCV is now highly curable, directly acting anti-viral treatments are costly and may not be accessible to many patients. To date, HIV remains a chronic disease without cure, and approximately half of Americans living with HIV are not engaged in care and are not virally suppressed. $^{8}$

Medication treatment for OUD has been shown to decrease overall mortality. ${ }^{9-11}$ Furthermore, among persons with OUD in addition to HIV and/or HCV, medication treatment of OUD can improve HIV and HCV outcomes. Among persons with HIV, treatments with buprenorphine and extended-release naltrexone are associated with antiretroviral therapy (ART) initiation ${ }^{12}$ and HIV viral suppression, ${ }^{13}$ respectively. Retention on buprenorphine is associated with enhanced HCV outcomes leading to cure. ${ }^{14}$ Treatment of OUD with medications is also associated with lower rates of $\mathrm{HCV}^{15-17}$ and $\mathrm{HIV}^{18,19}$ transmission.

The purpose of this study — conducted across 6 large health systems - was to describe the prevalence of recognized OUDs and office-based medication treatment for OUD among four groups of primary care patients: those with HCV only, HIV only, both HCV and HIV, and neither of these infections. Additionally, we sought to examine whether patients with OUD who had HCV (irrespective of HIV) and HIV (irrespective of $\mathrm{HCV}$ ) would be more likely to receive office-based medication treatment for OUD compared to patients without.

\section{METHODS}

\section{Study Design and Sample}

In this cross-sectional study, we ascertained data from the electronic health record (EHR) and insurance claims from six healthcare systems across five states $(\mathrm{CO}, \mathrm{CA}, \mathrm{OR}, \mathrm{WA}$, and MN). The data were collected for Phase 1 of the PRimary care Opioid Use Disorders (PROUD) Study (CTN 0074), a pragmatic trial testing whether a collaborative care model increases OUD medication treatment in primary care. Phase 1 of PROUD was a feasibility study in 11 health systems. Of the 11 sites, only 6 health systems were able to obtain complete phase 1 data needed for this study: HealthPartners (MN), MultiCare (WA), and 4 regions of Kaiser Permanente (WA, $\mathrm{CO}$, Northern CA, Northwest). Of these sites, 5 were integrated health insurance plans and delivery systems with data obtained from both EHRs and insurance claims and linkable dispensed medications from internal pharmacies, and one (MultiCare) was a community healthcare system which provided data only from the EHR. Each health system had linkable data on patient demographics, diagnoses, procedures, and utilization from all settings (e.g., outpatient, inpatient, urgent care, and emergency department), as well as pharmacy dispensing or medication orders. Medication use was determined by pharmacy dispensing data for the five integrated health systems and by medication orders for MultiCare. Diagnoses were based on International Classification of Disease9th edition (ICD-9-CM; until September 30, 2015) or ICD-10CM diagnostic codes (starting October 1, 2015).

The study sample included individuals with $\geq 2$ visits to primary care who were adults $\geq 18$ years of age within fiscal years 2014-2016. Primary care was defined via site of care: it included ambulatory visit encounter type where the department was either family practice, internal medicine, pediatrics, or gerontology. The study was approved by the Kaiser Permanente Washington (KPWA) institutional review board (IRB), and had a waiver of informed consent and HIPAA authorization. The remaining health systems ceded to the KPWA IRB.

\section{Measures}

Documented OUD. The primary outcome was a documented OUD diagnosis based on ICD-9 and/or ICD-10 codes (see Appendix) associated with clinical encounters identified from EHRs or insurance claims at any time in the 3-year study period. Codes for "active" or "in remission" OUD were included as providers can differ and use either OUD diagnosis coding (e.g., active vs. remission) when characterizing patients who are receiving medication treatment for OUD. Categories for "active" and "remission" were not mutually exclusive, as status could change during the study period. Patients with no documented ICD code for OUD but a prescription for transmucosal buprenorphine used to treat OUD were also considered to have a documented OUD.

Medication Treatment of OUD. The secondary outcome was receipt of any office-based medication treatment for OUD documented in the EHR or claims, defined as any documented prescription (pharmacy dispensing or order) with buprenorphine, including transmucosal or implanted, with or without naloxone at any time during the 3 -year study period 
from any prescriber. Buprenorphine transdermal patches, approved by the Food and Drug Administration for pain, were excluded. As a secondary treatment outcome, oral or injectable naltrexone based on a procedure code, medication order, or pharmacy dispensing was considered medication treatment for OUD if patients had a documented OUD diagnosis. This study of office-based medication treatment for OUD did not include methadone, as methadone is not sanctioned for treatment of OUD outside of federally regulated opioid treatment programs (OTPs) in the USA.

HIV/HCV Status. The main independent variable was documentation during the 3-year study of $\mathrm{HCV}$ and/or HIV diagnosis based on ICD-9 and/or ICD-10 codes. Patients were placed in one of 4 mutually exclusive groups based on whether they had any diagnosis for HCV and/or HIV documented at least once during the study period: HCV only, HIV only, both $\mathrm{HIV}$ and HCV, and neither HCV nor HIV.

Other Covariates. Age, gender, race (white, African American, Asian, Native American/Alaska Native, Hawaiian/Pacific Islander, Multiracial, and Other), ethnicity (Hispanic vs. non-Hispanic), and type of health insurance (Medicare, Private, State-subsidized, and Uninsured) were determined at the time of study entry (i.e., initial primary care visit to a study clinic during the study). Diagnoses were determined by ICD codes in the EHRs or insurance claims during the 3-year study period. Mental health disorder diagnoses included documentation of ICD codes for depression, anxiety, bipolar disorder, and schizophrenia. Substance use disorders (SUDs) included ICD codes for tobacco, alcohol, and other substances, including cannabis, stimulants, and other drugs. ICD codes were used to document any non-cancer pain diagnoses. We defined pain with ICD codes based on a validation study that used chart reviews across 13 primary care sites of a statewide federally qualified health center, and categorized types based on "diagnostic clusters" of pain. ${ }^{20}$,

${ }^{21}$ Counts of prescription opioids dispensed or ordered during the study period were used to assess opioid use. Acute care during the study period was categorized based on counts of days hospitalized or visits to emergency department, including urgent care $(0,1,2$, and $\geq 3)$.

\section{Statistical Analysis}

We conducted descriptive analyses of demographics and clinical characteristics across the four mutually exclusive HIV/ $\mathrm{HCV}$ groups. For each of the $4 \mathrm{HCV} / \mathrm{HIV}$ groups, the prevalence $(95 \%$ confidence intervals $[\mathrm{CI}])$ of having an OUD diagnosis documented in the EHR or claims during the 3year study period, and the prevalence of office-based medication treatment for OUD at any time during the 3-year study among primary care patients were calculated. To assess whether either HCV or HIV was independently associated with documented office-based medication treatment of OUD among patients with OUD, multivariate logistic regression was performed to examine the adjusted relative odds of receipt of medication treatment for OUD for patients with and without $\mathrm{HCV}$, and with and without HIV. Models included both binary variables (HIV yes/no; HCV yes/no) simultaneously and adjusted for site, age, gender, and race/ethnicity. These analyses were specified a priori. All analyses were conducted using Stata version 15.1 (College Station, TX).

\section{RESULTS}

The study sample included 1,368,604 adult primary care patients. Of those, $10,042(0.73 \%)$ were diagnosed with $\mathrm{HCV}$ alone, $5821(0.43 \%)$ with HIV alone, $422(0.03 \%)$ with both HCV and HIV, and 1,352, 319 (98.81\%) with neither. Those patients diagnosed with $\mathrm{HCV}$ and/or HIV were predominantly male, and over 45 years of age and a relatively higher proportion of patients in those groups were African-American compared to the group without HCV and HIV (Table 1). Diagnosed substance use disorders (alcohol, tobacco, cannabis, stimulant, and other), mental health disorders, and noncancer pain were all more common among persons with $\mathrm{HCV}$ and HIV compared to those without.

The prevalence of documented OUD was highest in patients with $\mathrm{HCV}$, both among those with $\mathrm{HCV}$ alone and those with HCV and HIV: $11.9 \%$ (95\% CI: $11.3 \%, 12.5 \%)$ and $8.8 \%$ (95\% CI: $6.2 \%, 11.9 \%$ ), respectively (Table 2 ). The lowest prevalence of documented OUD was in those with neither HCV nor HIV $(0.92 \%$; $95 \%$ CI: $0.91 \%, 0.94 \%)$. The prevalence among those with HIV alone was also low $(1.6 \%$; $95 \%$ CI: $1.3 \%, 2.0 \%)$. Most OUD was characterized by an active diagnosis code (Table 2).

Table 3 describes the prevalence of ordered or dispensed office-based medication treatment for OUD among the sample of patients who had been diagnosed with an OUD for each of the four groups based on HCV and HIV. Buprenorphine was the most frequently prescribed medication treatment for OUD in all groups. Among patients with OUD who were diagnosed with HCV only and patients who were not diagnosed with $\mathrm{HCV}$ or HIV, the prevalence of any medication treatment for OUD was $20.9 \%$ (95\% CI: $18.6 \%, 23.3 \%$ ) and $22.3 \%$ (95\% CI: $21.5 \%, 23.0 \%$ ), respectively. The prevalence of medication treatment for OUD was $16.0 \%$ (95\% CI: $9.2 \%, 25.0 \%$ ) in those with OUD and HIV, and $10.8 \%$ (95\% CI: $3.0 \%, 25.4 \%$ ) in those with OUD and both HIV/HCV.

In models adjusted for age, gender, race/ethnicity, and site, those with HIV had lower relative odds of ordered or dispensed medication treatment for OUD (adjusted odds ratio $[\mathrm{aOR}]=0.43 ; 95 \%$ CI: $0.26,0.72)$ compared to those without HIV, whereas the relative odds of receiving medication treatment for OUD were no different among persons with $\mathrm{HCV}$ $(\mathrm{aOR}=1.03 ; 95 \% \mathrm{CI}(0.88,1.21))$, compared to those without HCV (Appendix). Post hoc analyses excluding patients with 
Table 1 Characteristics of Primary Care Patients in 6 Healthcare Systems by HCV and HIV Status

\begin{tabular}{|c|c|c|c|c|}
\hline & $\begin{array}{l}\mathrm{HCV} \\
\text { alone }\end{array}$ & $\begin{array}{l}\text { HIV } \\
\text { alone }\end{array}$ & $\begin{array}{l}\text { Both } \\
\text { HCV } \\
\text { and HIV }\end{array}$ & $\begin{array}{l}\text { Neither } \\
\text { HCV nor } \\
\text { HIV }\end{array}$ \\
\hline Characteristics & $\begin{array}{l}n= \\
10,042\end{array}$ & $\begin{array}{l}n= \\
5821\end{array}$ & $n=422$ & $n=1352,319$ \\
\hline Age, years & $\%$ & & & \\
\hline $18-25$ & 1.7 & 4.0 & 1.2 & 10.4 \\
\hline $26-35$ & 3.5 & 13.6 & 5.5 & 16.0 \\
\hline $36-45$ & 7.4 & 22.2 & 18.5 & 16.1 \\
\hline $46-55$ & 27.0 & 34.3 & 39.3 & 18.5 \\
\hline $56-65$ & 46.3 & 19.5 & 30.1 & 19.3 \\
\hline $66-75$ & 10.9 & 5.7 & 5.0 & 12.0 \\
\hline$>75$ & 3.2 & 0.9 & 0.5 & 7.6 \\
\hline Female & 42.8 & 9.8 & 11.8 & 57.1 \\
\hline \multicolumn{5}{|l|}{ Race } \\
\hline Hispanic & 8.5 & 14.5 & 12.8 & 9.4 \\
\hline White & 64.5 & 62.6 & 57.1 & 68.7 \\
\hline African American & 13.2 & 12.0 & 20.4 & 5.8 \\
\hline Asian & 7.0 & 4.7 & 3.3 & 10.0 \\
\hline Native American/ & 1.0 & 0.4 & 0.5 & 0.4 \\
\hline \multicolumn{5}{|l|}{ Alaska Native } \\
\hline Hawaiian/Pacific & 0.4 & 0.5 & 0.2 & 0.5 \\
\hline \multicolumn{5}{|l|}{ Islander } \\
\hline Multiracial & 2.4 & 2.2 & 2.1 & 1.8 \\
\hline Other & 0.8 & 0.3 & 0.9 & 0.8 \\
\hline Unknown & 2.3 & 2.8 & 2.6 & 2.6 \\
\hline \multicolumn{5}{|l|}{ Insurance type } \\
\hline Medicare & 28.7 & 20.2 & 30.5 & 25.1 \\
\hline Private & 57.5 & 74.5 & 59.9 & 68.0 \\
\hline State subsidized & 12.1 & 3.9 & 8.6 & 5.0 \\
\hline Uninsured & 1.7 & 1.4 & 1.0 & 2.0 \\
\hline $\begin{array}{l}\text { Tobacco use } \\
\text { disorder }\end{array}$ & 50.9 & 26.2 & 48.8 & 16.0 \\
\hline $\begin{array}{l}\text { Alcohol use } \\
\text { disorder }\end{array}$ & 19.0 & 7.9 & 13.0 & 3.6 \\
\hline Other substance & 19.6 & 10.4 & 26.5 & 2.3 \\
\hline \multicolumn{5}{|l|}{ use disorders } \\
\hline Cannabis & 5.9 & 3.1 & 5.5 & 1.1 \\
\hline Stimulant & 7.6 & 6.6 & 20.6 & 0.6 \\
\hline Other substances & 14.0 & 5.3 & 16.1 & 1.3 \\
\hline $\begin{array}{l}\text { Mental health } \\
\text { disorder diagnosist }\end{array}$ & 49.3 & 47.1 & 58.3 & 33.1 \\
\hline $\begin{array}{l}\text { Non-cancer pain } \\
\text { diagnosis }\end{array}$ & 88.5 & 71.0 & 81.0 & 75.4 \\
\hline \multicolumn{5}{|c|}{ Any opioid dispensing } \\
\hline 0 orders & 35.5 & 52.6 & 36.3 & 59.6 \\
\hline $1-5$ orders & 34.6 & 35.1 & 39.3 & 32.1 \\
\hline $6-11$ orders & 8.6 & 4.9 & 7.6 & 3.4 \\
\hline $12+$ orders & 21.3 & 7.5 & 16.8 & 4.8 \\
\hline \multicolumn{5}{|c|}{ Emergency department visits* } \\
\hline 0 & 48.7 & 63.7 & 40.1 & 67.3 \\
\hline 1 & 19.4 & 18.4 & 23.7 & 17.7 \\
\hline 2 & 10.3 & 7.9 & 10.7 & 6.9 \\
\hline $3+$ & 21.6 & 9.9 & 25.5 & 8.1 \\
\hline \multicolumn{5}{|l|}{ Hospitalizations } \\
\hline 0 & 72.0 & 85.0 & 69.2 & 86.0 \\
\hline 1 & 13.8 & 8.7 & 15.9 & 8.5 \\
\hline $2+$ & 5.8 & 3.0 & 7.1 & 3.0 \\
\hline $3+$ & 8.4 & 3.3 & 7.8 & 2.5 \\
\hline
\end{tabular}

* Excludes data from Health Partners

**Excludes buprenorphine

tIncludes anxiety, depression, bipolar disorder, and schizophrenia
Table 3 Among Primary Care Patients Diagnosed with OUDs in 6 Healthcare Systems, Percentage Office-Based Medications for OUD by HCV and HIV Status

\begin{tabular}{|c|c|c|c|c|}
\hline & $\begin{array}{l}\text { HCV only } \\
(n=1194)\end{array}$ & $\begin{array}{l}\text { HIV } \\
\text { only } \\
(n=94)\end{array}$ & $\begin{array}{l}\text { Both } \\
\text { HCV } \\
\text { and } \\
\text { HIV } \\
(n=37)\end{array}$ & $\begin{array}{l}\text { Neither } \\
\text { HCV nor } \\
\text { HIV } \\
(n=12,462)\end{array}$ \\
\hline $\begin{array}{l}\text { Medication } \\
\text { type* }\end{array}$ & \multicolumn{4}{|c|}{$\%(95 \% \mathrm{CI})$} \\
\hline Buprenorphine & $\begin{array}{l}19.1(16.9, \\
21.4)\end{array}$ & $\begin{array}{l}11.7 \\
(6.0, \\
20.0)\end{array}$ & $\begin{array}{l}10.8 \\
(3.0, \\
25.4)\end{array}$ & $\begin{array}{l}20.3(19.6, \\
21.0)\end{array}$ \\
\hline Oral naltrexone & $\begin{array}{l}1.8(1.1, \\
2.7)\end{array}$ & $\begin{array}{l}3.2(0.7, \\
9.0)\end{array}$ & $\begin{array}{l}0.0(0.0 \\
9.5)\end{array}$ & $2.5(2.2,2$. \\
\hline $\begin{array}{l}\text { Injectable } \\
\text { naltrexone }\end{array}$ & $\begin{array}{l}1.1(0.6, \\
1.9)\end{array}$ & $\begin{array}{l}1.1(0.0, \\
5.8)\end{array}$ & $\begin{array}{l}0.0(0.0 \\
9.5)\end{array}$ & $0.9(0.8,1.1)$ \\
\hline $\begin{array}{l}\text { Any office- } \\
\text { based medica- } \\
\text { tion treatment } \\
\text { for OUD }\end{array}$ & $\begin{array}{l}20.9 \\
23.3)\end{array}$ & $\begin{array}{l}16(9.2 \\
25.0)\end{array}$ & $\begin{array}{l}10.8 \\
(3.0, \\
25.4)\end{array}$ & $\begin{array}{l}22.3(21.5, \\
23.0)\end{array}$ \\
\hline
\end{tabular}

*The number of patients on individual medications is not mutually exclusive as patients may have been ordered or dispensed more than one medication during the study period

evidence of chronic prescription opioid use - defined as 6 or more prescriptions for opioids during the study period - who might be misdiagnosed as having OUD on the basis of physical dependence alone revealed a similar pattern with prevalence lowest among persons living with HIV, although the prevalence of medications was higher overall in all groups, ranging from 20.0 to $31.6 \%$.

\section{DISCUSSION}

Among patients receiving primary care in six large healthcare systems, those diagnosed with HCV and HIV were more likely to have recognized OUD compared to uninfected patients. The prevalence of recognized OUD was low among patients without HCV and HIV (0.92\%); persons with HIV had nearly twice the prevalence (1.6\%) and persons with HCV had approximately 12 -fold higher prevalence (11.9\%). Approximately one-fifth of patients diagnosed with OUD received medication treatment for OUD; HCV was not associated with receipt of medication treatment for OUD, but patients with HIV were less likely to receive medication treatment for OUD compared to those without HIV.

No prior study has assessed the prevalence of recognized OUD and OUD treatment among primary care patients with $\mathrm{HCV}$ or HIV to the authors' knowledge. A recent study of data

Table 2 Among Primary Care Patients in 6 Healthcare Systems, Percentage with Diagnosed Opioid Use Disorder (OUD) by HCV and HIV Status

\begin{tabular}{lllll}
\hline \hline & $\begin{array}{l}\text { HCV alone } \\
(\boldsymbol{n}=\mathbf{1 0 , 0 4 2})\end{array}$ & $\begin{array}{l}\text { HIV alone } \\
(\boldsymbol{n}=\mathbf{5 8 2 1})\end{array}$ & $\begin{array}{l}\text { Both HCV and HIV } \\
(\boldsymbol{n}=\mathbf{4 2 2})\end{array}$ & $\begin{array}{l}\text { Neither HCV nor HIV } \\
(\boldsymbol{n}=\mathbf{1 , 3 5 2 , 3 1 9 )}\end{array}$ \\
\hline \% (95\% CI) & & & & \\
Any OUD & $11.9(11.3,12.5)$ & $1.6(1.3,2.0)$ & $8.8(6.2,11.9)$ & $0.92(0.91,0.94)$ \\
Active OUD* & $10.6(10.0,11.2)$ & $1.5(1.2,1.9)$ & $6.9(4.7,9.7)$ & $0.86(0.84,0.87)$ \\
OUD in remission* & $4.2(3.8,4.6)$ & $0.36(0.22,0.55)$ & $3.8(2.2,6.1)$ & $0.23(0.22,0.24)$ \\
\hline
\end{tabular}

*Active and remission OUDs are not mutually exclusive as individuals could have received more than one diagnosis code during the study period 
on 830,825 Veterans Health Administration patients who screened positive for unhealthy alcohol use in an outpatient setting observed that $15.6 \%$ of patients with $\mathrm{HCV}$ had an OUD diagnosis compared to $3.6 \%$ of those without $\mathrm{HCV}, 22$ which is higher than what we observed. A study of 10,652 adults with HIV who received screening for substance use at HIV clinics across the USA found that the prevalence of opioid use disorder was $4 \% .^{23}$

The finding of higher prevalence of OUD among persons with $\mathrm{HCV}$ and $\mathrm{HIV}$ in the present study is not surprising given the overlap in risk factors for these diseases. In the USA, HCV is predominantly spread through injection drug use, and in recent years $\mathrm{HCV}$ cases have dramatically risen as a result of the growing opioid epidemic. ${ }^{24}$ While sexual transmission of HIV is still the primary mode of transmission, approximately 1 in 10 new HIV diagnoses in the USA are attributed wholly or in part to injection drug use, ${ }^{25}$ and outbreaks of HIV related to injecting opioids have recently been reported. ${ }^{26-28}$ As such, having HCV or HIV is a marker for patients who are at risk for past or current OUD. Another partial explanation for the higher prevalence of OUD among persons with HCV and HIV is that these diseases can lead to painful complications (such as neuropathy and arthritis), which may have resulted in receipt of opioids for pain and subsequent addiction. Chronic pain and chronic use of opioids are common among persons with $\mathrm{HCV}^{29-31}$ and HIV. ${ }^{32-34}$ As our data demonstrate, there is also a higher prevalence of SUD and mental health disorders among persons with $\mathrm{HCV}$ and HIV, which are known risk factors for OUD among persons prescribed opioids. ${ }^{35}$ Finally, patients with HIV and HCV may have more frequent interactions with healthcare systems due to their infections, and thus have more opportunities for identifying OUD.

The public health significance of treatment of OUD in patients with HCV or HIV might justify specifically targeting these patients for OUD treatment. Untreated addiction may be associated with injection drug use and other high-risk behaviors that can lead to transmission of those infections. ${ }^{5,} 6$ Furthermore, medications for OUD can keep patients with $\mathrm{HIV}$ and $\mathrm{HCV}$ engaged in care resulting in better disease outcomes. ${ }^{12-14}$ However, this study found that primary care patients with HCV and HIV are not more likely than those without those infections to receive medication treatment for OUD, and those with HIV were less likely.

Our results which demonstrate low rates of receipt of treatment overall are consistent with other studies. National data suggest that less than a fifth of patients with OUD will receive any form of treatment for OUD. ${ }^{36}$ A study using Cigna commercial claims from 2014 to 2015 reported that approximately one-quarter of patients with OUD received pharmacotherapy, ${ }^{37}$; and among veterans who had been diagnosed with OUD in $2017,35 \%$ were on medication treatment for OUD. ${ }^{38}$ In a community-based sample of persons who injected opioids of which the majority had HCV, past year treatments with methadone and buprenorphine were reported by $27 \%$ and $5 \%$ respectively. ${ }^{39} \mathrm{~A}$ recent study of national commercial insurance claims data found that while the overall number of patients diagnosed with OUD increased from 2010 to 2014, the proportion of person-time covered by medications decreased from 25 to $16 \% .^{40}$

It is somewhat surprising that patients with OUD who had HIV in this study were less likely to be treated with medication treatment for OUD compared to uninfected patients. The results of the present study are consistent with those of a recently published study of Veterans Affairs patients which demonstrated that persons living with HIV were less likely to receive timely opioid agonist therapy compared to those who did not have HIV. ${ }^{41}$ Prior research has demonstrated numerous barriers to implementing buprenorphine treatment in HIV clinics, including workforce and training issues, ${ }^{42}$ and an absence of discussions about substance use between patients and HIV providers. ${ }^{43}$ It is a limitation of the current study that we were unable to capture OUD treatment with methadone that occurs in OTPs. It is possible persons living with HIV are more likely to be treated with methadone, although data on this are conflicting. ${ }^{44,}{ }^{45}$ Providers might have heightened concerns about polypharmacy, which is a risk in this population, ${ }^{46}$ or for hepatotoxicity despite demonstrated safety of medications used to treat OUD. ${ }^{47,48}$ Alternatively, there might be fewer HIV providers who are waivered and prescribe buprenorphine. Integrated models of care have been shown to close gaps in both the OUD and HIV care continuum, ${ }^{49-51}$ and such programs only existed within some clinics within these healthcare systems. Further work is needed to explore the barriers to OUD care among persons living with HIV.

There are limitations to the current study. Our results were based on diagnosis codes - we are unable to say what the true prevalence of active OUD is among these patient populations. Studies relying on EHR and claims data will likely underestimate the true prevalence of OUD in primary care as undercoding of behavioral health diagnoses is common. ${ }^{52-55}$ However, it is also possible that misclassification could occur in the opposite direction with accidental coding of OUD among patients with physical dependence of opioids due to longterm use. The higher prevalence of OUD in patients with $\mathrm{HCV}$ might reflect ascertainment bias. However, it is appropriate for providers to assess for OUD when caring for patients with known HCV and HIV given that injection drug use is an underlying risk factor for both diseases. Our definition of having HCV and HIV is based on diagnosis codes and similarly subject to misclassification: there were undoubtedly patients with those infections who had not been diagnosed, particularly for $\mathrm{HCV}$ which is an asymptomatic chronic infection. A study using nationally representative data from 2001 to 2008 found that approximately half of individuals with HCV were not aware of their infection, ${ }^{56}$ although more individuals may have been aware at the time of this study given the increased attention to HCV screening. The study did not capture data on medication treatment for OUD obtained outside the five health systems that were also insurers if a claim was not submitted (e.g., self-pay). Care outside the one 
community health systems was also not captured regardless of insurance. We are unable to say what fraction of these patients with OUD were receiving methadone and whether that differed by $\mathrm{HCV}$ and HIV status. However, the previously mentioned study of commercial claims data found that adding in methadone data only increased the absolute percentage receiving pharmacotherapy for OUD by a few percentage points. ${ }^{37}$ The sample of patients with HIV was relatively small, leading to relatively wide confidence intervals for estimates of OUD treatment. Persons living with HIV who received their primary care exclusively within specialty clinics may not be captured in the sample; therefore, results may not be fully representative. Also, this study was conducted among a largely privately insured population limiting generalizability to other populations or settings. Furthermore, whether co-pays or requirements for prior authorization were a barrier to access to OUD treatment is not known. Finally, as this was a cross-sectional study, we cannot infer causality for associations observed between HCV and HIV diagnoses and use of office-based medication treatment for OUD. The timing of these diagnoses relative to diagnoses of OUD was not assessed, as well as continuity of care, both of which could impact medication receipt.

In summary, among patients receiving primary care in 6 large healthcare systems, those who were diagnosed with HCV and HIV were more likely to have documented OUD compared to uninfected patients, with the highest prevalence (11.9\%) occurring among patients with HCV. Receipt of medication treatment for OUD was uniformly low for all patients, including those with HCV and HIV, with only up to one-fifth of patients with OUD receiving buprenorphine or naltrexone. The finding that patients with HIV who had OUD were less likely to receive medication treatment for OUD compared to uninfected patients was unexpected and merits further investigation. These results highlight the need for improved access to medications for OUD, particularly from providers caring for patients living with $\mathrm{HCV} /$ HIV. Providing effective treatment for OUD is critical for maximizing the health of persons living with HIV and HCV, as well as preventing transmission of these diseases.

Corresponding Author: Katharine A. Bradley, MD, MPH; Kaiser Permanente Washington Health Research Institute, 1730 Minor Avenue, STE 1600, Seattle, WA 98101 (206) 948-1933, USA (e-mail: katharine.a.bradley@kp.org).

Supplementary Information The online version contains supplementary material available at https://doi.org/10.1007/s11606-020 06389-7.

Funding Research reported was supported by the National Institute on Drug Abuse of the National Institutes of Health Award Numbers UG1DA040314, UG1DA040316, U1O DAO13714, 5UG1DA013035, UG1-DA015831, UG1DA020024, and U10-DA13720.

\section{Compliance with Ethical Standards:}

Disclaimer: The content is solely the responsibility of the authors and does not necessarily represent the official views of the National Institutes of Health.
Conflict of Interest: Dr. Bobbi Jo H. Yarborough has received support through her institution from Syneos Health to conduct FDA-mandated post-marketing research on the risks of opioid analgesic use. Dr. Cynthia Campbell has received research support through her institution from the Industry PMR Consortium, a consortium of companies working together to conduct post-marketing studies required by the Food and Drug Administration that assess known risks related to opioid analgesic use.

\section{REFERENCES}

1. Centers for Disease Control and Prevention. Drug Overdose Deaths. 2018. Available at: https://www.cdc.gov/drugoverdose/data/ statedeaths.html. Accessed 5/14/2018 2019.

2. Substance Abuse and Mental Health Services Administration. Key Substance Use and Mental Health Indicators in the United States: Results from the 2017 National Survey on Drug Use and Health., Rockville, MD. 2018. Available at: https://www.samhsa.gov/data/report/2017-nsduh-annual-national-report.

3. Compton WM, Jones CM, Baldwin GT. Relationship between Nonmedical Prescription-Opioid Use and Heroin Use. N Engl J Med 2016;374(2):154-63. https://doi.org/10.1056/NEJMra1508490

4. Potter JS, Marino EN, Hillhouse MP, Nielsen S, Wiest K, Canamar CP, et al. Buprenorphine/naloxone and methadone maintenance treatment outcomes for opioid analgesic, heroin, and combined users: findings from starting treatment with agonist replacement therapies (START). J Stud Alcohol Drugs 2013;74(4):605-13

5. Zibbell JE, Asher AK, Patel RC, Kupronis B, Iqbal K, Ward JW, et al. Increases in Acute Hepatitis C Virus Infection Related to a Growing Opioid Epidemic and Associated Injection Drug Use, United States, 2004 to 2014. Am J Public Health 2018;108(2):175-81. https://doi.org/10. 2105/ajph.2017.304132

6. Peters PJ, Pontones P, Hoover KW, Patel MR, Galang RR, Shields J, et al. HIV Infection Linked to Injection Use of Oxymorphone in Indiana, 2014-2015. N Engl J Med 2016;375(3):229-39. https://doi.org/10. 1056/NEJMoa 1515195

7. Ly KN, Hughes EM, Jiles RB, Holmberg SD. Rising Mortality Associated With Hepatitis C Virus in the United States, 2003-2013. Clin Infect Dis 2016;62(10):1287-8. https://doi.org/10.1093/cid/ciw111

8. National Center for HIV/AIDS VH, STD, and TB Prevention. HIV in the United States: At a Glance. Centers for Disease Control. 2018. Available at: https://www.cdc.gov/hiv/pdf/statistics/overview/cdc-hiv-usataglance.pdf. Accessed Jun 2018.

9. Hickman M, Steer C, Tilling K, Lim AG, Marsden J, Millar T, et al. The impact of buprenorphine and methadone on mortality: a primary care cohort study in the United Kingdom. Addiction. 2018;113(8):1461-76. https://doi.org/10.1111/add.14188

10. Ma J, Bao YP, Wang RJ, Su MF, Liu MX, Li JQ, et al. Effects of medication-assisted treatment on mortality among opioids users: a systematic review and meta-analysis. Mol Psychiatry 2018. https://doi. org/10.1038/s41380-018-0094-5

11. National Academies of Sciences Engineering and Medicine, Health and Medicine Division, Board on Health Sciences Policy, Committee on Medication-Assisted Treatment for Opioid Use Disorder. In: Mancher M, Leshner AI, editors. Medications for Opioid Use Disorder Save Lives. Washington (DC) 2019.

12. Altice FL, Bruce RD, Lucas GM, Lum PJ, Korthuis PT, Flanigan TP, et al. HIV treatment outcomes among HIV-infected, opioid-dependent patients receiving buprenorphine/naloxone treatment within HIV clinical care settings: results from a multisite study. J Acquir Immune Defic Syndr 2011;56 Suppl 1:S22-32. https://doi.org/10.1097/QAI. Ob013e31820975le

13. Springer SA, Di Paola A, Azar MM, Barbour R, Biondi BE, Desabrais M, et al. Extended-Release Naltrexone Improves Viral Suppression Among Incarcerated Persons Living With HIV With Opioid Use Disorders Transitioning to the Community: Results of a Double-Blind, PlaceboControlled Randomized Trial. J Acquir Immune Defic Syndr 2018;78(1):43-53. https://doi.org/10.1097/QAI.0000000000001634

14. Norton BL, Beitin A, Glenn M, DeLuca J, Litwin AH, Cunningham CO Retention in buprenorphine treatment is associated with improved HCV care outcomes. J Subst Abus Treat 2017;75:38-42. https://doi.org/10. 1016/j.jsat.2017.01.015 
15. Nolan S, Dias Lima V, Fairbairn N, Kerr T, Montaner J, Grebely J, et al. The impact of methadone maintenance therapy on hepatitis C incidence among illicit drug users. Addiction. 2014;109(12):2053-9. https://doi.org/10.1111/add.12682

16. White B, Dore GJ, Lloyd AR, Rawlinson WD, Maher L. Opioid substitution therapy protects against hepatitis $\mathrm{C}$ virus acquisition in people who inject drugs: the HITS-c study. Med J Aust 2014;201(6):326-9

17. Tsui JI, Evans JL, Lum PJ, Hahn JA, Page K. Association of opioid agonist therapy with lower incidence of hepatitis $\mathrm{C}$ virus infection in young adult injection drug users. JAMA Intern Med 2014;174(12): 197481. https://doi.org/10.1001/jamainternmed.2014.5416

18. Gowing L, Farrell MF, Bornemann R, Sullivan LE, Ali R. Oral substitution treatment of injecting opioid users for prevention of HIV infection. Cochrane Database Syst Rev. 2011(8):Cd004145. https://doi. org/10.1002/14651858.CD004145.pub4

19. MacArthur GJ, Minozzi S, Martin N, Vickerman P, Deren S, Bruneau $\mathbf{J}$, et al. Opiate substitution treatment and HIV transmission in people who inject drugs: systematic review and meta-analysis. BMJ. 2012;345:e5945. https://doi.org/10.1136/bmj.e5945

20. Interagency Pain Research Coordinating Committee. National Pain Strategy: A Comprehenisve Population Health-Level Strategy for Pain. In: Department of Health and Human Services, editor. Washington, DC 2015

21. Tian TY, Zlateva I, Anderson DR. Using electronic health records data to identify patients with chronic pain in a primary care setting. J Am Med Inform Assoc 2013;20(e2):e275-80. https://doi.org/10.1136/amiajnl2013-001856

22. Owens MD, Ioannou GN, Tsui JL, Edelman EJ, Greene PA, Williams EC. Receipt of alcohol-related care among patients with $\mathrm{HCV}$ and unhealthy alcohol use. Drug Alcohol Depend 2018;188:79-85. https:// doi.org/10.1016/j.drugalcdep.2018.03.047

23. Hartzler B, Dombrowski JC, Crane HM, Eron JJ, Geng EH, Christopher Mathews W, et al. Prevalence and Predictors of Substance Use Disorders Among HIV Care Enrollees in the United States. AIDS Behav 2017;21(4):1138-48. https://doi.org/10.1007/s10461-016-1584-6

24. National Center for HIV/AIDS VH, STD, and TB Prevention. New Hepatitis C Infections Nearly Tripled over Five Years. https://www.cdc. gov/nchhstp/newsroom/2017/Hepatitis-Surveillance-Press-Release. html2017

25. National Center for HIV/AIDS VH, STD, and TB Prevention. Injection Drug Use and HIV Risk. 2018. Available at: https://www.cdc.gov/hiv/ risk/idu.html. Accessed Jun 10, 2020

26. Conrad C, Bradley HM, Broz D, Buddha S, Chapman EL, Galang RR, et al. Community outbreak of HIV infection linked to injection drug use of oxymorphone-Indiana, 2015. MMWR Morb Mortal Wkly Rep 2015;64(16):443-4

27. Cranston K, Alpren C, John B, Dawson E, Roosevelt K, Burrage A, et al. Notes from the Field: HIV Diagnoses Among Persons Who Inject Drugs - Northeastern Massachusetts, 2015-2018. MMWR Morb Mortal Wkly Rep. 2019;68(10):253-4. https://doi.org/10.15585/mmwr. mm6810a6

28. Golden MR, Lechtenberg R, Glick SN, Dombrowski J, Duchin J, Reuer JR, et al. Outbreak of Human Immunodeficiency Virus Infection Among Heterosexual Persons Who Are Living Homeless and Inject Drugs Seattle, Washington, 2018. MMWR Morb Mortal Wkly Rep. 2019;68(15):344-9. https://doi.org/10.15585/mmwr.mm6815a2

29. Whitehead AJ, Dobscha SK, Morasco BJ, Ruimy S, Bussell C, Hauser P. Pain, substance use disorders and opioid analgesic prescription patterns in veterans with hepatitis C. J Pain Symptom Manag 2008;36(1):39-45. https://doi.org/10.1016/j.jpainsymman.2007.08.013

30. Tsui JI, Cheng DM, Libman H, Bridden C, Samet J. Hepatitis C virus infection is associated with painful symptoms in HIV-infected adults. AIDS Care 2012;24(7):820-7. https://doi.org/10.1080/09540121.2011. 642989

31. Tsui JI, Herman DS, Kettavong M, Anderson BJ, Stein MD. Chronic pain and hepatitis $\mathrm{C}$ virus infection in opioid dependent injection drug users. J Addict Dis 2011;30(2):91-7. https://doi.org/10.1080/ 10550887.2011.554775

32. Edelman EJ, Gordon $\mathbf{K}$, Becker WC, Goulet JL, Skanderson M, Gaither JR, et al. Receipt of opioid analgesics by HIV-infected and uninfected patients. J Gen Intern Med 2013;28(1):82-90. https://doi. org/10.1007/s11606-012-2189-Z

33. Merlin JS. Chronic Pain in Patients With HIV Infection: What Clinicians Need To Know. Top Antiviral Med 2015;23(3):120-4

34. Merlin JS, Long D, Becker WC, Cachay ER, Christopoulos KA Claborn K, et al. Brief Report: The Association of Chronic Pain and
Long-Term Opioid Therapy With HIV Treatment Outcomes. J Acquir Immune Defic Syndr 2018;79(1):77-82. https://doi.org/10.1097/QAI. 0000000000001741

35. Edlund MJ, Steffick D, Hudson T, Harris KM, Sullivan M. Risk factors for clinically recognized opioid abuse and dependence among veterans using opioids for chronic non-cancer pain. Pain. 2007;129(3):355-62. https://doi.org/10.1016/j.pain.2007.02.014

36. Wu LT, Zhu H, Swartz MS. Treatment utilization among persons with opioid use disorder in the United States. Drug Alcohol Depend 2016;169:117-27. https://doi.org/10.1016/j.drugalcdep.2016.10.015

37. Thomas CP, Ritter GA, Harris AHS, Garnick DW, Freedman KI, Herbert B. Applying American Society of Addiction Medicine performance measures in commercial health insurance and services data. J Addict Med 2018;12(4):287-94. https://doi.org/10.1097/ADM. 0000000000000408

38. Wyse JJ, Gordon AJ, Dobscha SK, Morasco BJ, Tiffany E, Drexler K, et al. Medications for opioid use disorder in the Department of Veterans Affairs (VA) health care system: Historical perspective, lessons learned, and next steps. Subst Abus 2018;39(2):139-44. https://doi.org/10. 1080/08897077.2018.1452327

39. Tsui JI, Burt R, Thiede H, Glick SN. Utilization of buprenorphine and methadone among opioid users who inject drugs. Subst Abus 2017:1-6. https://doi.org/10.1080/08897077.2017.1363844

40. Morgan JR, Schackman BR, Leff JA, Linas BP, Walley AY. Injectable naltrexone, oral naltrexone, and buprenorphine utilization and discontinuation among individuals treated for opioid use disorder in a United States commercially insured population. J Subst Abus Treat 2018;85:906. https://doi.org/10.1016/j.jsat.2017.07.001

41. Wyse JJ, Robbins JL, McGinnis KA, Edelman EJ, Gordon AJ, Manhapra A, et al. Predictors of timely opioid agonist treatment initiation among veterans with and without HIV. Drug Alcohol Depend 2019;198:70-5. https://doi.org/10.1016/j.drugalcdep.2019.01.038

42. Finkelstein R, Netherland J, Sylla L, Gourevitch MN, Cajina A, Cheever L, et al. Policy implications of integrating buprenorphine/ naloxone treatment and HIV care. J Acquir Immune Defic Syndr 2011;56 Suppl 1:S98-S104. https://doi.org/10.1097/QAI.0b013e31820a9a97

43. Korthuis PT, Josephs JS, Fleishman JA, Hellinger J, Himelhoch S, Chander G, et al. Substance abuse treatment in human immunodeficiency virus: the role of patient-provider discussions. J Subst Abus Treat 2008;35(3):294-303. https://doi.org/10.1016/j.jsat.2007.11.005

44. Manhapra A, Quinones L, Rosenheck R. Characteristics of veterans receiving buprenorphine vs. methadone for opioid use disorder nationally in the Veterans Health Administration. Drug Alcohol Depend 2016;160:82-9. https://doi.org/10.1016/j.drugalcdep.2015.12.035

45. Fingerhood MI, King VL, Brooner RK, Rastegar DA. A comparison of characteristics and outcomes of opioid-dependent patients initiating office-based buprenorphine or methadone maintenance treatment. Subst Abus 2014;35(2):122-6. https://doi.org/10.1080/08897077.2013. 819828

46. Edelman EJ, Gordon KS, Glover J, McNicholl IR, Fiellin DA, Justice AC. The next therapeutic challenge in HIV: polypharmacy. Drugs Aging 2013;30(8):613-28. https://doi.org/10.1007/s40266-013-0093-9

47. Tetrault JM, Tate JP, Edelman EJ, Gordon AJ, Lo Re V, 3rd, Lim JK, et al. Hepatic Safety of Buprenorphine in HIV-Infected and Uninfected Patients With Opioid Use Disorder: The Role of HCV-Infection. J Subst Abus Treat 2016;68:62-7. https://doi.org/10.1016/j.jsat.2016.06.002

48. Mitchell MC, Memisoglu A, Silverman BL. Hepatic safety of injectable extended-release naltrexone in patients with chronic hepatitis $\mathrm{C}$ and HIV infection. J Stud Alcohol Drugs 2012;73(6):991-7

49. Rich KM, Bia J, Altice FL, Feinberg J. Integrated Models of Care for Individuals with Opioid Use Disorder: How Do We Prevent HIV and HCV? Curr HIV/AIDS Rep 2018;15(3):266-75. https://doi.org/10.1007/ s11904-018-0396-X

50. Durvasula R, Miller TR. Substance abuse treatment in persons with HIV/AIDS: challenges in managing triple diagnosis. Behav Med 2014;40(2):43-52. https://doi.org/10.1080/08964289.2013.866540

51. Walley AY, Palmisano J, Sorensen-Alawad A, Chaisson C, Raj A, Samet $\mathbf{J H}$, et al. Engagement and Substance Dependence in a Primary Care-Based Addiction Treatment Program for People Infected with HIV and People at High-Risk for HIV Infection. J Subst Abus Treat 2015;59:59-66. https://doi.org/10.1016/j.jsat.2015.07.007

52. Walley AY, Farrar D, Cheng DM, Alford DP, Samet JH. Are opioid dependence and methadone maintenance treatment (MMT) documented in the medical record? A patient safety issue. J Gen Intern Med 2009;24(9):1007-11. https://doi.org/10.1007/s11606-009-1043-4 
53. Kim HM, Smith EG, Stano CM, Ganoczy D, Zivin K, Walters H, et al. Validation of key behaviourally based mental health diagnoses in administrative data: suicide attempt, alcohol abuse, illicit drug abuse and tobacco use. BMC Health Serv Res 2012;12:18. https://doi.org/10. 1186/1472-6963-12-18

54. Steele LS, Glazier RH, Lin E, Evans M. Using administrative data to measure ambulatory mental health service provision in primary care. Med Care 2004;42(10):960-5

55. Valenstein M, Ritsema T, Green L, Blow FC, Mitchinson A, McCarthy JF, et al. Targeting quality improvement activities for depression. Implications of using administrative data. J Fam Pract 2000;49(8):721-8
56. Denniston MM, Klevens RM, McQuillan GM, Jiles RB. Awareness of infection, knowledge of hepatitis C, and medical follow-up among individuals testing positive for hepatitis C: National Health and Nutrition Examination Survey 2001-2008. Hepatology. 2012;55(6):1652-61. https://doi.org/10.1002/hep.25556

Publisher's Note: Springer Nature remains neutral with regard to jurisdictional claims in published maps and institutional affiliations. 